\title{
Management of hybridization in an endemic species: decision making in the face of imperfect information in the case of the black wildebeest - Connochaetes gnou
}

\author{
J. Paul Grobler ${ }^{1}$ Ian Rushworth ${ }^{2} \cdot$ James S. Brink $^{3,4} \cdot$ Antoinette Kotze $^{1,5} \cdot$ Paulette Bloomer $^{6} \bullet$ \\ Brian Reilly ${ }^{7} \cdot$ Savvas Vrahimis $^{8}$
}

\begin{abstract}
${ }^{1}$ Department of Genetics, University of the Free State, P.O. Box 339, Bloemfontein, 9300 South Africa
${ }^{2}$ Ecological Advice Division, Ezemvelo KwaZulu-Natal Wildlife, PO Box 13053, Cascades 3202, South Africa.

${ }^{3}$ Florisbad Quaternary Research, National Museum, P.O. 266, Bloemfontein, South Africa ${ }^{4}$ Centre for Environmental Management, University of the Free State, P.O. Box 339, Bloemfontein, 9300, South Africa

${ }^{5}$ National Zoological Gardens of South Africa, PO Box 754, Pretoria, 0001 South Africa

${ }^{6}$ Department of Genetics, University of Pretoria, Private bag X20, Hatfield, Pretoria 0028, South Africa

${ }^{7}$ Department of Nature Conservation, Tshwane University of Technology, P/Bag X680, Pretoria 0001, South Africa ${ }^{8}$ Free State Department of Economic Development, Tourism, \& Environmental Affairs, P/Bag X20801, Bloemfontein, 9300, South Africa
\end{abstract}

\begin{abstract}
Hybridization between introduced and endemic ungulates, resulting from Anthropogenic actions, have been reported for several species. Several studies of such events contain the common themes of extralimital movements, problematic phenotypic and genetic detection, and imperfect management. In southern Africa, the endemic black wildebeest (Connochaetes gnou) currently faces a serious threat of hybridization and introgression. This species survived near extinction and consequent genetic bottlenecks in the late 1800s and in the 1930s. Initiatives by private farmers followed by conservation authorities led to a dramatic recovery in numbers of this species. However, in an ironic twist, the very same advances in conservation and commercial utilisation which lead to the recovery of numbers are now themselves threatening the species. Injudicious translocation has brought the species into contact with its congener, the blue wildebeest (Connochaetes taurinus), and in recent times, hybridization between the species has occurred at numerous localities in South Africa. Consequently, a significant proportion of the national black wildebeest population potentially carries a proportion of introgressed blue wildebeest genetic material. We discuss completed and ongoing attempts to
\end{abstract}


find molecular markers to detect hybrids and highlight the difficulty of detecting advanced backcrosses. Additional avenues of research, such as work on morphology (cranial and postcranial elements), estimating of the probability of introgression and modelling of diffusion rates are also introduced. In addition to the difficulty in detecting hybrid animals or herds, the lack of consensus on the fate of hybrid herds is discussed. Finally, in an environment of imperfect information, we caution against implementation of management responses that will potentially induce a new genetic bottleneck in C. gnou.

Key words Connochaetes gnou, C.taurinus, Black wildebeest, Hybridization, Introgression

\section{Introduction}

\section{Hybridization and endemic species}

Anthropogenic actions have led to the removal of barriers to reproduction among several ungulates species, with examples of hybridization reported from Europe, North America and Africa. For example, multiple hybridization events involving native red deer red (Cervus elaphus) and introduced Japanese sika deer (Cervus nippon) in the United Kingdom have been described by Abernethy (1994), Goodman et al. (1999), McDevitt et al. (2009), Pérez-Espona et al. (2009), Senn and Pemberton (2009) and others. Similarly, a history of hybridization (though initially intentional) poses a significant threat to the genetic integrity of the bison (Bison bison) in North America, as reviewed by Hedrick (2009). In South Africa, hybridization between blackand blue wildebeest (Connochates gnou and Connochates taurinus) has been widely reported (Fabricius et al. 1988, Grobler et al. 2005, Ackermann et al. 2010), while hybrids between blesbok and bontebok (Damaliscus dorcas philipsi and D. pygargus pygargus) have also been observed (Brooke et al. 1986). Several common themes arise from the available published accounts of hybridization. These include the role of translocations and extralimital introductions breaking down geographical isolation, the difficulties in detecting advanced backcrosses involving hybrids, and the complexity of management strategies needed to prevent further incidents and manage extant hybrid individuals. In this paper, we review the specific circumstances surrounding the origin, detection and management of hybridization involving the two wildebeest species of the genus Connochaetes. 


\section{Evolution and conservation history of $C$. gnou}

The black wildebeest is endemic to southern Africa, with a range that formerly included parts of South Africa, Lesotho and Swaziland (Fig. 1) (Brink 2005; Skinner and Chimimba 2005). C. gnou is believed to have originated from a blue wildebeest-like ancestor, with the two lineages leading to the modern forms splitting approximately 1 million years ago (Corbet and Robinson 1991; Brink 1993, 2005). Blue wildebeest are widely distributed in southern and east Africa (Skinner and Chimimba 2005). The two species share the same chromosome number $(2 n=58)$ (Buckland and Evans 1978), have many morphological similarities (Skinner and Chimimba 2005) and are trophically indistin indistinguishable (Codron and Brink 2007). Externally, the two species are most readily distinguished by horn conformation (Fig2a, c): the black wildebeest has horns with expanded bases that curve primarily forwards and downwards, and the curve up at the ends whereas the blue wildebeest has horns that sweep laterally and slightly downwards, then curve up at the ends and sometimes back towards the skull. There are also differences relating to body size and the characteristics of the coat (colour and length of hair). Black wildebeest are obligate grassland species, whereas blue wildebeest will use open grassland and savanna/bushland (Skinner and Chimimba 2005). Distributions of the two species overlapped periodically after the speciation of the black wildebeest, but habitat preferences and behavioural differences contributed to reproductive isolation (Brink et al 1999; Brink 2005). The historical distribution ranges of both species are shown in Fig. 1.

Hunting pressure, habitat reduction due to human settlement and the expansion of agriculture, as well as disease outbreaks, brought $C$. gnou to the brink of extinction by the late 1800's and early 1900's (Von Richter 1971a). By 1899, the species had disappeared from most parts of its former range (Von Richter 1971a). Furthermore, a devastating drought in 1933 had a severe impact on this species. Von Richter (1971b) provides information from one population where only 15-20 animals, mainly males, survived out of a population of approximately 400 animals, which provides evidence of a second bottleneck. Overall, an estimated 300 animals survived by 1938 (Kirkman 1938). Total extinction, however, was prevented through the actions of conservation-minded farmers (Stokes 1942; Von Richter 1971b), and subsequent actions by conservation authorities. In recent times the total population size has been estimated at over 18,000 animals (IUCN 2008) of which many now occur outside the native range. The IUCN status of C. gnou has also improved from "vulnerable" in 1994 to "lower risk / conservation 
a.

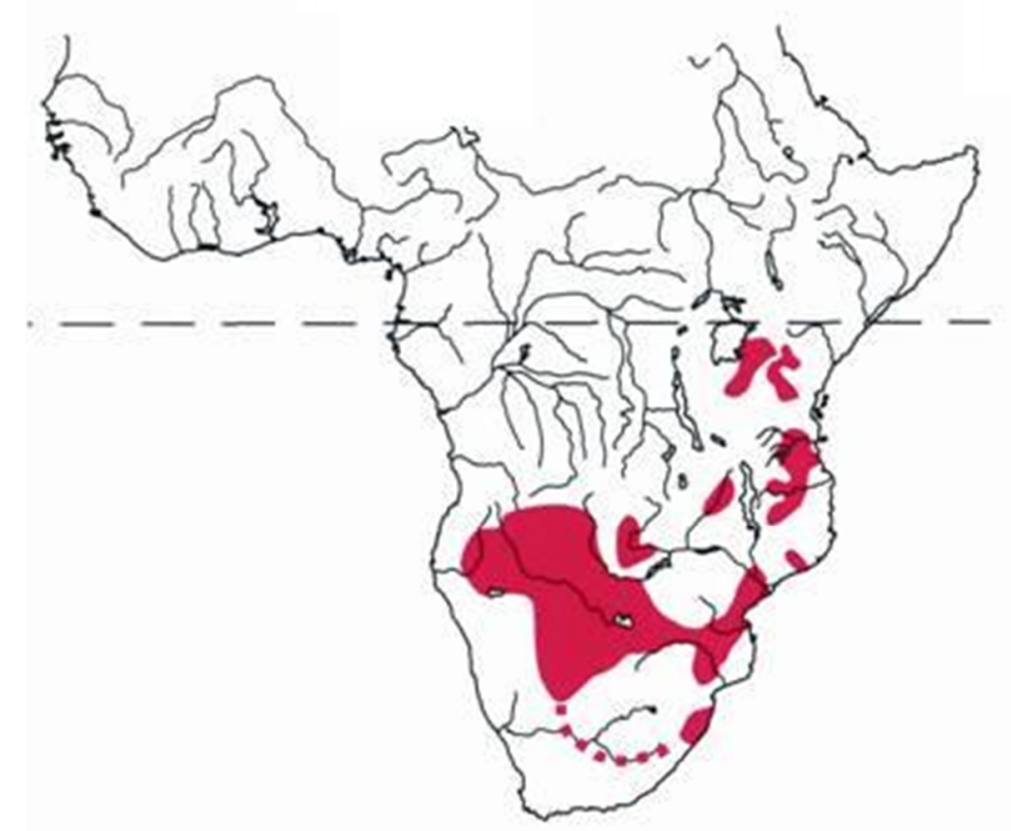

b.

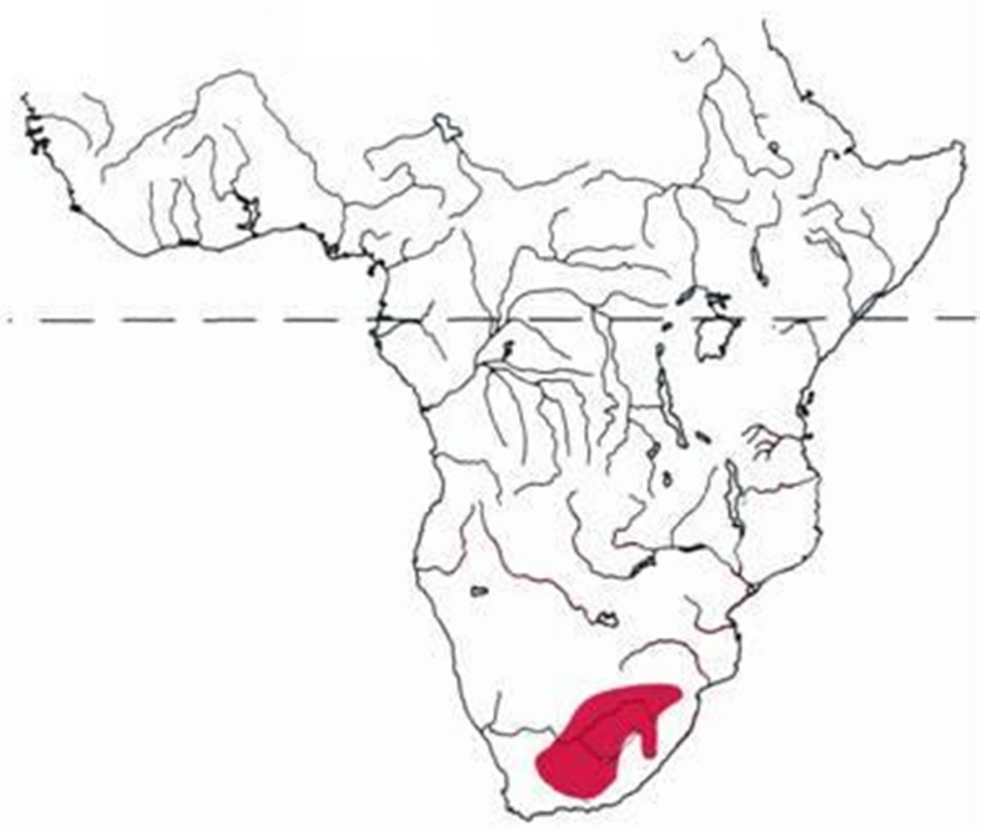

Fig. 1 Maps of sub-Saharan Africa showing the historic distributions of blue wildebeest (a) and black wildebeest (b). The Holocene fossil record of blue wildebeest and historic records, indicated by the broken line in a, suggests substantial natural overlap with black wildebeest. (After Brink 2005, adapted from Kingdon 1997) 
dependent" in 1996 to "least concern" from 2002 onwards. In contrast to C. gnou, blue wildebeest in South Africa were not decimated to the extent of its congener (Corbet and Robinson 1991) and currently large numbers are found in many regions of this country (Skinner and Chimimba 2005), including in many areas where they did not naturally occur.

\section{Hybridization}

South Africa has a long history of wildlife management that involves both state protected areas and private ownership of game animals on private land. Private ownership of wildlife has been shown to advance conservation objectives (McGranahan 2008) and the recovery actions that led to the saving of black wildebeest stand as one of the great conservation success stories of private landowners in South Africa. Indeed, in 1999, it was estimated that $80 \%$ of the extant population of this species occurred on private land (East 1999). The success of wildlife management has led to highly developed techniques for game capture and translocation, used by government agencies and private landowners alike. South Africa now has a substantial record of extralimital translocations of indigenous ungulates (Spear and Chown 2009), with frequent buying and selling of animals. The translocations include both species of wildebeest that have been widely translocated both within and outside their natural ranges. This practice also extends to the keeping of blue- and black wildebeest together on the same properties, on both state- and privately owned land.

Reproductive isolation may, however, disappear under the conditions typically found on small properties. Small fenced areas often have insufficient suitable habitat for one of the species, resulting in them sharing the same areas. In addition, unnatural sex ratios resulting from hunting and translocations may result in mate-choice changing where there is an absence of species-specific mates. Confirmation of fecund offspring from hybridization between black and blue wildebeest was first reported by Fabricius et al. (1988). The horn conformation of an F1 hybrid is shown in Fig. 2b. With subsequent unidirectional backcrosses, hybrids are indistinguishable at a distance from pure animals based on external phenotypic characters from the F2 or F3 generations onwards. However, osteologically, these can be detected. Limited available observational data suggests that initial hybridization events are mostly unidirectional, with matings involving blue wildebeest bulls and black wildebeest cows, but at least one case of 
a.

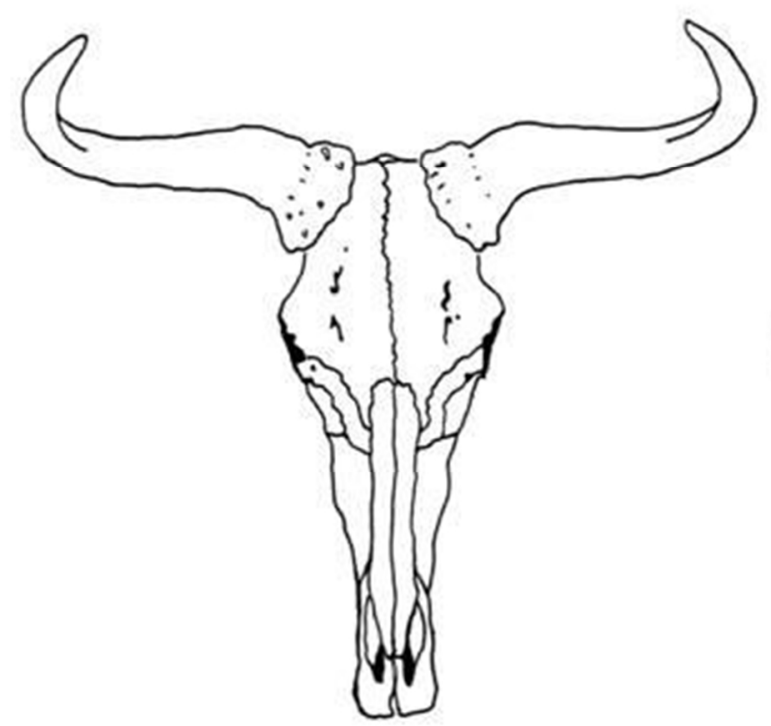

b.

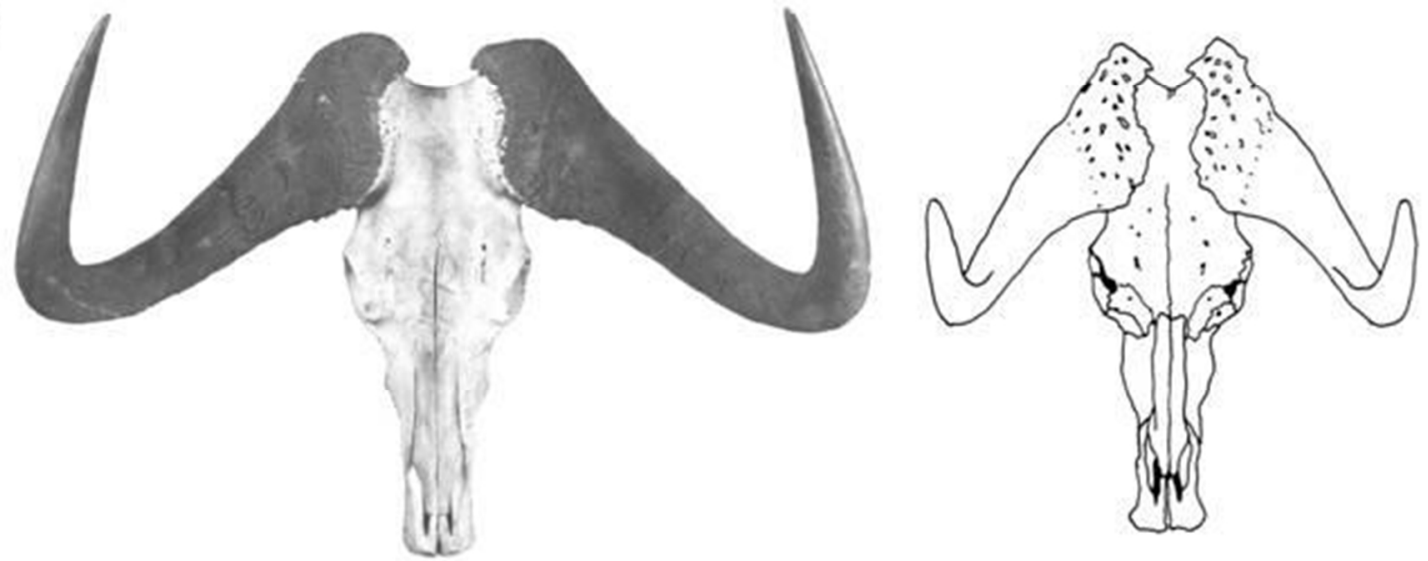

Fig. 2 The skulls of a male blue wildebeest (a) and a male black wildebeest (c), compared to a hybrid male skull (b), recovered from a private game farm in the Free State Province by SVand JSB. Although the hybrid specimen shows almost perfect intermediate morphology between black and blue wildebeest, hybrid morphology varies considerably, with pathologies commonly observed. The black and blue wildebeest skulls are from the Florisbad collections and date to the first half of the twentieth century, predating the problem of hybridization. Note that the comparative specimens (a and c) lack horn sheaths. (Modified after Brink 2005) 
black wildebeest bulls mating with blue wildebeest females (in a population without blue wildebeest bulls) has been recorded (Vrahmis, personal observation).

The history of the Polokwane Game Reserve in the Limpopo Province serves to illustrate the typical progression of hybridization events involving wildebeest (Grobler et al. 2005). In 1963 five black wildebeest from a known pure population (based on population history) were introduced to the reserve that already hosted a resident population of blue wildebeest. Concern over possible hybridization was raised by 1982 (Grobler et al. 2005), and the decision was taken to cull all wildebeest of both species on the reserve. However, between 1963 and 1982, 71 offspring of wildebeest on the reserve were translocated to six known new localities, including a state protected area. Some of the recipient localities, in turn also acted as source populations to found new populations, leading to rapid growth in the number of localities possibly hosting hybrid animals. In theory the permitting system for the movement of animals implemented by the provinces should allow for identification of these properties, but no attempt has ever been made to trace these properties or rectify the situation. Poor record keeping and illegal movement of animals by private game capture operators complicates retrospective management.

In the KwaZulu-Natal Province, black- and blue wildebeest were introduced into Spioenkop Nature Reserve; a state owned protected area owned by Ezemvelo KwaZulu-Natal Wildlife (EKZNW) as the responsible conservation agency. In 1995 two suspected hybrid animals were shot, prompting, in the absence of any genetic tests, capture of the entire herd of 160 animals for closer morphological inspection by experienced conservationists. The original plan was to cull any animals displaying obvious hybrid characteristics, but a large proportion of animals displayed horn, body size and colour characteristics not usual in pure herds. This led to the conclusion that hybridization had progressed beyond the F2 generation and was widespread throughout the population. In applying a principle that government protected areas should contain only guaranteed pure animals to ensure successful long-term black wildebeest conservation, a decision was made to cull the entire herd. Subsequent morphological analysis confirmed that the original decision to cull had been the correct one (Ackermann et al. 2010).

As in the case of Polokwane, a number of animals had been captured and translocated to three other state-owned protected areas (Coleford, Chelmsford and Kamberg Nature Reserves in KwaZulu-Natal) and an unknown number of private properties in the period that both species occurred together. Animals were also translocated from the three recipient nature reserves to an 
unknown number of other properties prior to a moratorium on live movement from any area where both species had occurred together being unilaterally imposed by the provincial conservation agency in 1996. A policy was subsequently adopted and implemented to reduce the risk of import of hybrid animals into the province, to limit the opportunities for further hybridization and to prevent translocation from properties where both species were known to occur. A limitation on the implementation of corrective measures was that many landowners had legally acquired both species (prior to knowledge about hybridization) and that no resources were allocated to sorting out hybrid or mixed populations and making decisions on their future. In response to increased awareness of the problem, the entire herd of black wildebeest in Midmar Nature Reserve were culled because there was a period of several years where they were mixed with blue wildebeest. They were replaced with supposed pure animals from the Free State, but recent findings now question whether that population itself was pure (Vrahamis, personal observation).

The Polokwane, Spioenkop and Midmar case studies are but three of many similar situations. Despite the increasing awareness of the problem, no conservation agencies other than EKZNW have, to date, adopted policies to minimise hybridization. Presently, it is estimated that there are more than 120 properties with both species in the Free State, Eastern Cape, Mpumalanga, Gauteng, Northern Cape and KwaZulu-Natal provinces of South Africa (Rushworth and Vrahimis, personal observation). Many thousands of black wildebeest, some of them possibly already carrying blue wildebeest genes, have been exported to Namibia, Botswana and Swaziland and, in most instances, are kept on properties with blue wildebeest. Hybridization has already been documented in one protected area in Swaziland (Rushworth and Vrahimis, personal observation). The numbers of properties reported here only includes those identified subsequent to highlighting the dangers of hybridization, and thus, the number of properties that formerly hosted both species is likely to be significantly higher. If hybridization had occurred at a significant number of these localities where the two species were historically or are currently kept together, and such hybrids were subsequently sold and translocated, a large proportion of the entire black wildebeest population of southern Africa potentially contains a significant proportion of introgressed blue wildebeest genetic material. 


\section{Discussion: approaches and limitations to detecting hybrids}

\section{Screening for hybrids}

The identification of hybrids under the circumstances described above presents a unique challenge to conservation managers. In contrast to relatively uncomplicated hybrid zones between established and introduced species, as for example the case of Grevy's zebra being swamped by plains zebra (Cordingly et al. 2009), hybridization in wildebeest involve numerous independent hybridization events at a large number of localities, a situation more closely comparable to the multiple hybridization events involving native red deer and introduced Japanese sika deer (Goodman et al. 1999, McDevitt et al. 2009, Pérez-Espona et al. 2009). However, even compared to these examples, the case of wildebeest in South Africa is probably unique in terms of the number of possible localities at which hybridization has potentially occurred, the regular movement of animals between populations and the lack of accurate documentation relating to population histories over several decades.

\section{History of genetic analysis of wildebeest}

The first studies aimed at finding marker-based differences between black- and blue wildebeest were published in the 1990s. Corbet and Robinson (1991) used mitotic chromosomes and mitochondrial DNA (mtDNA) and reported that no species-specific G-banded or C-banded chromosomal markers were found. These authors concluded that karyotypes of the two species are invariant at the level of resolution obtained. Corbet et al. (1994) found very low genetic distance between the two species, using allozymes, and concluded that blue- and black wildebeest appear to be at an early stage of evolutionary divergence. Grobler and Van der Bank (1995) also used protein-coding loci to study differentiation between the two species, as part of a

bigger study on genetic divergence in the subfamily Alcelaphinae. These authors reported allele frequency differences and some species-specific alleles at five polymorphic loci at low frequencies, but no fixed diagnostic species-specific alleles were found.

The first published account of an attempt to find microsatellite markers for hybrid wildebeest was reported by Grobler et al. (2005) (with work based on such primers was also undertaken at the University of Pretoria at the time). Grobler et al. (2005) used cross-species application of five bovid microsatellites and identified a number of potential species-specific 
alleles. Such cross-species application of primers between taxonomically close groups is well accepted (Wilson et al. 1997), and the approach is considered particularly useable in wildebeest that are relatively closely related to domestic cattle, for which a large number of markers exist. The results were used to support the hypothesis of limited introgression of $C$. taurinus genetic material into a herd of $C$. gnou (a population descendent from the Polokwane Game Reserve, as described above), corroborating the known management history of the specific population. Subsequent use of these markers with bigger sample sizes of pure reference populations (Grobler, unpublished results), confirmed that some alleles are indeed species-specific but also revealed that other alleles, deemed species-specific with the smaller sample size, are in fact shared by the two species. This outcome confirms the need for adequate reference populations when describing hybrids.

Any identification of species-specific markers in blue- and black wildebeest, irrespective of the specific marker(s) eventually used, will likely be based on relatively small differences, considering the close relationship between these two congeners. For this reason, it is critical that a very good overview of overall genetic diversity in each species is obtained. The allelic range obtained for each species based on pure populations may exclude shared alleles if sample size or geographic coverage is inadequate. This may result in false positives if a supposed "blue" allele is identified in a putative black wildebeest population, when in fact that specific allele was excluded from the profile for black wildebeest due to inadequate sampling. For the black wildebeest, it would be particularly important to identify and fully sample the few truly representative pure populations. The database for black wildebeest could also be supplemented by using museum material dating to before the bottlenecks and human movement of animals.

\section{The future of genetic analysis in wildebeest}

Several additional avenues for marker development exist and are currently being explored by laboratories in South Africa. These efforts are aimed both at developing markers with increased diagnostic power, and increasing the overall number of markers available, in order to make use of optimal approaches for statistical analyses (e.g. assignment tests - Pritchard et al. 2000; Manel et al. 2005). First, the development and use of de novo species-specific microsatellites rather than cross-species ones will probably improve the likelihood of uncovering species-specific alleles. In this regard, the set of microsatellite loci developed by Røed et al. (2011) for use in 
East African blue wildebeest may also be useful. Secondly, with evidence from observations suggesting that initial hybridization events involve a disproportionate fraction of blue wildebeest males mating with black cows, markers located on the Y-chromosome may also be informative. In this regard, Verklaar et al. (2003) stated that uniparentally inherited markers may detect the origin of a population even if generations of breeding has obscured the original species composition. Thirdly, single-nucleotide polymorphisms (SNPs) could also add valuable additional markers due to potentially high rates of polymorphism (Glover et al. 2010), and good potential to detect past demographic events, including admixture (Schlötterer 2004). SNP markers would be a particularly valuable approach to drastically increase the number of loci available, a vital requirement to ensure statistical significance of analyses (see below). A significant number of such loci would however be needed since more SNP loci are required compared to microsatellite markers, to detect structure at recent divergence times (Haasl and Payseur 2011). SNP markers also offer the advantage that raw data from different laboratories may be more readily comparable than those derived from microsatellites (Coates et al. 2009), a useful advantage if the workload of genotyping a large number of black wildebeest herds is to be shared by a number of separate laboratories. The high development cost of SNPs has been a limiting factor (Schlötterer 2004), but next generation sequencing is making this goal more attainable. Lasty, maternally inheritied mtDNA haplotypes in conjunction with morphology have been effectively used to identify hybrids in some species. The usefulness of mtDNA genes for studying hybridization in wildebeest is however likely to be limited due to the apparent biased or unidirectional hybridization (between blue wildebeest bulls and black wildebeest cows). Hybrids will contain black wildebeest mtDNA haplotypes, and introgression in backcrosses beyond F1 will thus not be detectable from markers in the mitochondrial genome. MtDNA variation would, however, be valuable to document the species history of the two taxa over evolutionary time scales, providing valuable insights for contributing to the development of sound longterm conservation plans.

There is a general expectation from conservation authorities and game farmers that sufficient research will inevitably yield a set of markers for the routine identification of pure or hybrid individuals within herds. While this is indeed attainable, we caution that such an outcome would potentially require a very large number of diagnostic markers, considering the timescale since hybridization started. In theory, each successive backcross generation should carry a 
proportion of introgressed genes comprising a quarter, eight, sixteenth, or less of the genome (Goodman et al. 1999). There will thus be a reduced probability of detection in each successive generation, and with diagnostic alleles already occurring at low frequencies in pure species, it will be hard to detect these in advanced backcrosses. In practise, the expected ratios will be distorted even further by processes such as selection and recombination occurring over generations. The use of multiple markers increases the chance of success, but there are also limitations.

Boecklen and Howard (1997) demonstrated that upwards of 70 independent markers are required to distinguish advanced backcrosses (four to five generations) from pure species at relatively low error. This was confirmed by Vähä and Primmer (2006) who found that up to 42 loci were necessary for accurate differentiation between hybrids, pure animals and backcrosses after only a few generations. There are almost certainly scenarios in wildebeest where the number of backcrosses since initial hybridization now exceeds five generations. In fact, in the KZN Province of South Africa, there are properties where hybridization potentially commenced in 1965 (Rushworth, pers observation). With female wildebeest being able to reproduce before the age of two years (Vrahimis, personal observation), 45 years could represent more than 20 generations of successive backcrosses.

From a financial perspective, it is also possible that the cost of sampling and analyses may approach the commercial value of animals themselves. Game farmers may thus decide to focus on other species rather than carry the financial burden of proving purity. Such a downscaling in wildebeest numbers on game farms would be an unfortunate reversal of the successful management history of the species over the last century. A more conservative approach might therefore be to aim to detect hybrid alleles in herds rather than individuals, and then classify the herd accordingly. For such an approach, Boecklen and Howard (1997) suggested that four or five microsatellite-type markers with fixed genetic differences between species should provide sufficient power if the objective is to categorize hybrid populations.

\section{A morphological approach: cranial and postcranial morphological anomalies}

From a morphological perspective, it has been shown that it is possible to identify unique features of the cranium and the postcranium in pure black and blue wildebeest (Brink pers. observation). This has been tested further in the hybrid population from Spioenkop (Ackermann 
et al. 2010). These authors detected anomalies in the dental, sutural and horn features of hybrids, but also in limb elements that confirm admixture. This approach, applied either alone or in conjunction with molecular data, can thus add valuable data on the existence of hybrid animals in populations. In a sample of the Maria Moroka black wildebeest population, which represents a hybrid population of an unknown number of generations (Vrahimis pers. observation), preliminary evidence suggests that cranial and postcranial hybrid characters became stabilised. Therefore, in this case hard tissue morphology has preserved a distinct hybrid signal several generations (number unknown) after the hybridization event. Screening of skeletal features thus shows considerable promise to detect hybrids, even backcrosses, though application of a method that requires skeletons from culled animals may have limitations in some management applications.

\section{Supplementary approaches}

To support the search for genetic markers, it will be beneficial to estimate the likelihood of hybridization occurring, given that the two species are present in the same enclosed area, through modelling of various scenarios. This probability will be influenced by factors such as the size of the area, the numbers of each species and - potentially the most important - the availability of species specific mates. Modelling of this kind will require a significant amount of field observations of behaviour on localities where both species occur. The data can then be correlated with physical features of the localities and population parameters, in effect leading to a landscape approach where the contributions of various physical, management and population factors to the likelihood of hybridization are quantified.

As an extreme test to gain data on both population processes and rates of introgression, researchers in South Africa have contemplated the concept of a deliberate hybridization experiment, under strictly controlled conditions. Such an experiment, with known starting parameters, would enable empiric monitoring of the progress and persistence of introgression after successive crosses. A limitation of this approach is that the number of variables in starting conditions is probably too high to include in a single experimental herd. Furthermore, researchand conservation authorities are not keen to commit to host such an experiment over the long term, in view of possible escapes and negative publicity from deliberately housing hybrid animals. Also, computer based simulations and diffusion models, for example tailor-made 
modifications of software such as SPIP (Anderson and Dunham, 2005) can possibly mirror the outcome of an empirical experiment without any of the associated risks.

We also recommend the kryopreservation of genetic material of pure animals of both species. As technology in reproductive biology matures, such an ex situ source could potentially be used to regenerate pure populations in futures (Holt and Pickard 1999).

\section{Management of hybrid wildebeest}

\section{Managing with imperfect information}

If unambiguous markers and analytical approaches for determining pure species should be found, the final hurdle will be to reach consensus on the management of extant wildebeest herds, which may then include a high component of hybrid herds. A purist approach would be to cull all hybrid animals, followed by a rigorous legislative regime to prevent new hybridization events. This would potentially be the most conclusive approach but there is the real possibility of inducing a new genetic bottleneck in $C$. gnou as a whole in the process. This could be catastrophic for genetic diversity in the species, since $C$. gnou passed through two bottlenecks in the last 110 years, and the 300 founders surviving the last bottleneck event were probably already quite highly related (Corbet and Robinson 1991). Possible proof of reduced levels of genetic diversity in C. gnou is evident from microsatellite-derived values published by Grobler et al. (2005). These authors observed an average heterozygosity of 0.348 and an average of 3.2 alleles per locus in a pooled sample of pure $C$. gnou individuals from South Africa, compared to values of 0.646 / 6.2 for a pooled sample of C. taurinus. Furthermore, Simberloff (1996) suggested that hybrid herds themselves may contain unique alleles in a species with low overall numbers.

Another more pragmatic, approach would be to tolerate the work on a continuum of genetic purity. In such a scenario, it could be argued that government controlled protected areas,

private protected areas and accredited private game farms would keep certified pure herds of black wildebeest only, whereas herds with moderate introgression of blue wildebeest genetic material would still be allowed on game farms geared to local sport hunting. This approach would prevent a genetic bottleneck involving the entire species, leaving more options for longterm developments that may arise in the technology of genetic screening and approaches in 
management. It will no doubt also find favour with farmers who would likely be willing to pay a premium for certified animals, to gain accredited status. A limitation of the more pragmatic approach would however be that the keeping of accurate records on translocations would be vital, to retain the distinction between the pure and hybrid black wildebeest populations. For this reason, conservation authorities may be reluctant to agree to a model where a component of hybrid animals is tolerated.

A radical intervention suggested by Hedrick (2009) is to deliberately introduce pure animals to hybrid herds, leading to the genetic swamping of introgressed alleles. This measure is dependent on the availability of significant numbers of pure animals. Considering the limited number of pure black wildebeest available in South Africa, and the official sentiment towards hybrid animals, it seems unlikely that such an approach is viable for wildebeest.

\section{Specific Management Recommendations}

We suggest that the following regulations be implemented to contain hybridization in southern African wildebeest until a final solution is found:

1. No properties should be permitted to keep both species of wildebeest, and where possible neighbouring properties should not have different species because of the high probability of animals not being contained by fences. Where there are already both species on one property then the blue wildebeest should be removed. Although dead removal would rule out any chance of hybrid animals being translocated into other populations, as blue wildebeest are less likely to have hybrid alleles, there may be some room for considering live removals subsequent to morphological screening of horn conformation and coat characteristics. The remaining black wildebeest population must be kept in isolation until a morphological and genetic assessment can assure purity.

2. Suspected hybrid herds must be isolated on properties with adequate fencing that are regularly inspected by the authorities, and no live offtake should be permitted until reliable genetic tests are in place and have been used to screen for hybrid genes. If the population is confirmed to contain hybrid alleles, then owners should be encouraged to remove all animals through hunting or culling; the government should consider purchasing hybrid herds to remove them quickly and permanently from the population, 
and to, in some measure, compensate those landowners who introduced both species with official sanction.

3. The few known pure populations (based on management history) must be registered, and strict measures should be put in place to control the introduction of animals into and translocation of animals from these populations (it would be undesirable for pure animals to then be introduced into hybrid herds). Accurate record keeping and a functional permit system are essential.

4. No animals must be removed live from government protected areas where there is a chance of hybridization having taken place or where hybrid animals may have been introduced. These populations must be assessed using morphological and current (imperfect) genetic criteria, and possibly through a few sacrificed animals criteria, and possibly through a few sacrificed animals or reasonable chance of hybridization having taken place, animals on government protected areas should be removed and replaced with pure animals, although a problem will remain to find a source of guaranteed pure animals.

5. There needs to be improved record keeping of movements of black wildebeest. Contrary to what is being demanded by the game ranching industry, the permitting system that regulates the movement of indigenous animals in South Africa must be maintained and, if anything, made more stringent. In particular, permits must very specifically record the exact source and destination of animals. Currently, many translocation permits are issued to game traders (middlemen) who then permit to sell and translocate animals to other properties, but in the process, the link between the original source and final destination of specific animals is often lost.

6. It is known that there are several game capture companies operating without relevant permission and who are moving animals without required permits. This makes keeping track of the movement of hybrid herds extremely difficult. We therefore suggest improved oversight and regulation of private game capture operations, and prosecution of those operating illegally.

7. Conservation agencies in South Africa should review the exportation of black wildebeest to neighbouring countries, as this drastically reduces the South African population, given 
the large numbers that are exported annually (especially to Namibia). This will also contribute to managing the hybridization risk in Namibia and Botswana.

Specific issues that still need to be addressed include deciding who funds genetic tests and who, in the case of hybrid herds, should carry the cost of the removal and replacement of animals. Clearly, government needs to allocate more resources to the process, including improving the permitting system and the ability to monitor its implementation.

The problem should, however, also be approached by understanding both the proximate and ultimate causes of hybridization. Presently, there are huge economic incentives for landowners to maximise the number of game species on one property for hunting and tourism purposes, and this is the ultimate driver for having both species of wildebeest together on one property. Spear and Chown (2009) note that it may be problematic for conservationists to make a case against activities such as extralimital translocations, when these activities result in substantial economic benefit. Until the market removes the aberrant incentive to maximise the number of species on a property, there will always be an incentive to keep both species of wildebeest together. When the market starts paying a premium for hunting animals living naturally within their historical distribution range, and avoids properties where trophy animals may be hybrids, then market forces will start encouraging landowners to act in the long-term conservation interest of the species. Until this happens, increased effort needs to be placed on implementing controls on animal movement using permits and other regulations, this in an environment where there are calls to reduce or completely remove state controls on the movement of large herbivores.

\section{Concluding remark}

With the wildebeest hybridization issue in southern Africa now several decades old, conservation authorities are eager to implement a solution. However, we have to caution that hasty management decisions based on partial information will not contribute to a lasting solution. In particular, large-scale culling on simple suspicion of hybridization is not recommended at this time, when criteria for neither hybrid identification nor management guidelines have been agreed on. As an interim step, we suggest that legislation focuses on containing the movement of existing putative hybrids, and rigorously prevent the keeping of mixed herds of blue- and black 
wildebeest so as to prevent new hybridization events from occurring. Ultimately, the aim should be to implement a management strategy that will conserve pure herds of $C$. gnou without repeating the bottleneck experienced by this species in the previous century.

\section{References}

Abernethy, K. 1994. The establishment of a hybrid zone between red and sika deer (genus Cervus). Mol. Ecol 3:551-562.

Ackermann RR, Brink JS, Vrahimis S, De Klerk B. (2010) Hybrid wildebeest (Artiodactyla: Bovidae) provide further evidence for shared signatures of admixture in mammalian crania. SA J Sci 106:1-5

Anderson EC, Dunham KK. (2005) Spip 1.0: a program for simulating pedigrees and genetic data in age-structured populations. Mol Ecol Notes 5:459-461

Boecklen WJ, Howard DJ. (1997) Genetic analysis of hybrid zones: numbers of markers and power of resolution. Ecology 78:2611-2616

Brink JS. (1993) Postcranial evidence for the evolution of the black wildebeest, Connochaetes gnou: an exploratory study. Palaeontol Afr 30:61-69

Brink JS, Berger LR, Churchill SE. (1999) Mammalian fossils from erosional gullies (dongas) in the Doring River drainage. Central Free State Province, South Africa. In: C. Becker, H. Manhart, J. Peters \& J. Schibler (eds.), Historium animalium ex ossibus. Beiträge zur Paläoanatomie, Archäologie, Ägyptologie, Ethnologie und Geschichte der Tiermedizin: Festschrift für Angela von den Driesch. Rahden/Westf : Verlag Marie Leidorf GmbH, 7990.

Coates BS, Sumerford DV, Miller NJ, Kim KS, Sappington TW, Siegfried BD, Lewis LC. (2009) Comparative performance of single nucleotide polymorphism and microsatellite markers for population genetic analysis. J Hered 100:556-564

Corbet SW, Robinson TJ. (1991) Genetic divergence in South African wildebeest: comparative cytogenetics and analysis of mitochondrial DNA. J Hered 82:447-452

Corbet SW, Grant WS, Robinson TJ. (1994) Genetic divergence in South African wildebeest: analysis of allozyme variability. J Hered 85:479-483

Cordingley JE, Sundaresan SR, Fischhoff IR, Shapiro B, Ruskey J, Rubenstein DI. (2009) Is the 
endangered grevy's zebra threatened by hybridization? Anim Conserv 12:505-513

East R. (1999) African Antelope Database 1999. IUCN, Gland, Switzerland and Cambridge, UK. Fabricius C, Lowry D, Van den Berg P. (1988) Fecund black wildebeest x blue wildebeest hybrids. SA J Wild Res 18:35-37

Glover KA, Hansen MM, Lien S, Als TD, Høyheim B, Skaala O. (2010) A comparison of SNP and STR loci for delineating population structure and performing individual genetic assignment. BMC Genet 11:2

Goodman SJ, Barton NH, Swanson G. Abernethy K, Pemberton JM. (1999) Introgression through rare hybridization: a genetic study of a hybrid zone between red and sika deer (genus Cervus) in Argyll, Scotland. Genetics 152:355-371

Grobler JP, Van der Bank FH. (1995) Allozyme divergence between four representatives of the sub-family Alcelaphinae (Family: Bovidae). Comp Biochem Physiol 112B:303-308

Grobler JP, Hartl GB, Grobler N, Kotze A, Botha K, Tiedemann R. (2005) The genetic status of an isolated black wildebeest (Connochaetes gnou) population from the Abe Bailey Nature Reserve, South Africa: Microsatellite data on a putative past hybridization with blue wildebeest (C. taurinus). Mamm Biol 70: 35-45

Hedrick PW. (2009) Conservation genetics and the North American bison (Bison bison). J Hered 100:411-420

Holt WG, Pickard AR. (1999) Role of reproductive technologies and genetic resource banks in animal conservation. Rev Reprod 4:143-150

IUCN. (2008) IUCN SSC Antelope Specialist Group 2008. Connochaetes gnou. In: IUCN 2010. IUCN Red List of Threatened Species.

Kirkman AHB. (1938) Conservation notes. Connochaetes gnou. J Soc Pres Fauna Emp 35:50

Manel S, Gaggiotti OE, Waples RS. (2005) Assignment methods: matching biological questions with appropriate techniques. TREE 20:136-142

McGranahan DA. (2008) Managing private, commercial rangelands for agricultural production and wildlife diversity in Namibia and Zambia. Biodiversity Conserv 17:1965-1977

Pritchard JK, Stephens M, Donnelly P. (2000) Inference of population structure using multilocus genotype data. Genetics 155:945-959

Schlötterer C. (2004) The evolution of molecular markers - just a matter of fashion? Nature Rev Genet 5:63-70 
Senn HV, Pemberton JM. (2009) Variable extent of hybridization between invasive sika (Cervus nippon) and native red deer (C. elaphus) in a small geographical area. Mol ecol 18:862876

Skinner JD, Chimimba CT. (2005) The Mammals of the Southern African subregion. 3rd edition. Cambridge University Press.

Spear D, Chown SL. (2009) The extent and impacts of ungulate translocations: South Africa in a global context. Biol Conserv 142:353-363

Stokes CS. (1942) Sanctuary. The Cape Times Limited, Cape Town. 472pp.

Verklaar ELC, Vervaecke H, Roden C, Mendoza R, Barwegen MW, Susilawati T, Nijman IJ, Lenstra JA. (2003) Paternally inherited markers in bovine hybrid populations. Heredity 91:565-569

Von Richter W. (1971a) Connochaetes gnou. Mamm Species 50:1-6

Von Richter W. (1971b) Past and present distribution of the black wildebeest, Connochaetes gnou Zimmerman (Artiodactyla: Bovidae) with special reference to the history of some herds in South Africa. Annls Transv Mus 27:35-57

Wilson GA, Strobeck C, Wu L, Coffin JW. (1997) Characterization of microsatellite loci in caribou Rangifer tarandus, and their use in other Artiodactyls. Mol Ecol 6:697-699 